\title{
Cortex Moutan Inhibits Bladder Cancer Cell Proliferation and Expression of Angiogenic Factors
}

\author{
Mei-Yi Lin 1,2, Cheng-Huang Shen",4, Su-Yin Chiang1, Syue-Yi Chen3, Yu-Shih Lin', \\ Cheng-Da Hsu ${ }^{3 *}$ \\ ${ }^{1}$ Graduate Institute of Chinese Medicine, College of Chinese Medicine, China Medical University, Taichung, \\ Taiwan \\ ${ }^{2}$ Department of Chinese Medicine, Ditmanson Medical Foundation Chia-Yi Christian Hospital, Chia-Yi, Taiwan \\ ${ }^{3}$ Department of Medical Research, Ditmanson Medical Foundation Chia-Yi Christian Hospital, Chia-Yi, Taiwan \\ ${ }^{4}$ Department of Urology, Ditmanson Medical Foundation Chia-Yi Christian Hospital, Chia-Yi, Taiwan \\ ${ }^{5}$ Department of Chinese Medicine Pharmacy, Chiayi Chang Gung Memorial Hospital, Chia-Yi, Taiwan \\ Email: ${ }^{*}$ cych06390@gmail.com
}

Received 6 June 2014; revised 5 July 2014; accepted 21 July 2014

Copyright (C) 2014 by authors and Scientific Research Publishing Inc.

This work is licensed under the Creative Commons Attribution International License (CC BY). http://creativecommons.org/licenses/by/4.0/

(c) (i) Open Access

\section{Abstract}

Metastases are the main cause of death among patients with bladder cancer, which is the second most common malignancy of the genitourinary tract and is highly prevalent in the southwestern region of Taiwan. Angiogenesis plays a critical role in tumor growth and metastasis processes and has relevance in disease recurrence, pelvic lymph node metastasis and poor prognosis. Cancer cells can produce several angiogenesis-stimulating factors involved in vascular growth, including vascular endothelial growth factor (VEGF), basic fibroblast growth factor (bFGF), and inflammatory cytokines such as interleukin (IL)-8. Common chemotherapeutic drugs for intravesical instillations usually cause major side effects, including urinary frequency, urinary urgency, cystitis, and hematuria. In order to identify a less cytotoxic therapeutic agent that can inhibit tumor cell proliferation, we examined the traditional Chinese herbal medicine Cortex Moutan-reported to have antibacterial, antiviral, anti-inflammatory, antithrombotic, and antitumor properties-for its effects on bladder cancer cell proliferation and expression of angiogenic factors. Our results revealed that Cortex Moutan exhibited high selectivity in inhibiting the growth of bladder cancer cells and also reduced the expression of angiogenesis-stimulating factors in those cells. Thus, we suggest that Cortex Moutan might be used as a cancer therapy drug for bladder's intravesical chemotherapy in the future.

\footnotetext{
${ }^{*}$ Corresponding author.
} 


\section{Keywords}

\section{Cortex Moutan, BFTC 905 Cells, TSGH 8301 Cells, Growth Inhibition, VEGF, bFGF, IL-8}

\section{Introduction}

Among cancers of the urothelium, or the epithelial lining of the urinary tract, urothelial carcinoma (formerly known as transitional cell carcinoma before the World Health Organization's 2004 terminology update [1]) is by far the most common type, accounting for approximately $90 \%$ of the cases, followed by squamous cell carcinoma, about 5\%, and adenocarcinoma, about 2\% [2]. Bladder cancer is the second most common malignancy of the urogenital system, with over $90 \%$ of bladder cancers being urothelial carcinoma [3]. The risk factors for bladder cancer have been shown to include exposure to chemicals such as hair dyes and arylamines, long-term occupational exposure to dyes, rubber, leather, textiles, and paints [4] [5], drinking arsenic-contaminated water [6] [7], and smoking tobacco [8]. In Taiwan, the highest incidence of bladder cancer is found in the southwestern region encompassing Yunlin and Chiayi counties, especially in the coastal areas [6]; however, the etiologic factors present in this region are still not fully understood. Approximately $80 \%$ of bladder cancers are superficial, involving the mucosal or submucosal layer but not the muscle layers of the bladder, while the remaining cases are muscle-invasive or metastatic [2] [9]. Chemotherapy for superficial bladder cancer involves the intravesical instillation of chemotherapeutic drugs. Treatment for invasive bladder cancer commonly includes preoperative or postoperative adjuvant chemotherapy or combined radiation and chemotherapy, and palliative chemotherapy may be given in the case of metastatic disease [10]. Intravesical chemotherapy for stage 0 or 1 superficial bladder cancer is usually administered within 24 hours after transurethral resection, and the common chemotherapeutic agents used include cisplatin, doxorubicin, mitomycin C, and bacillus Calmette-Guerin (BCG). However, instillations with these drugs often cause bothersome side effects such as cystitis, urinary frequency, urinary urgency, and hematuria [10] [11]. Therefore, exploring traditional Chinese medicine for agents that are effective against bladder cancer but with fewer side effects has the potential to greatly improve the care for bladder cancer patients.

The majority of deaths from bladder cancer are related to metastases [12]. Angiogenesis plays a crucial role in tumor growth, progression, and metastasis and is correlated with disease recurrence, pelvic lymph node metastasis, and poor prognosis [13]. It has been shown that vascular endothelial growth factor (VEGF) is more highly expressed in bladder tumors than that in normal bladder tissue, and the expression level of VEGF is higher in superficial bladder tumors than that in invasive bladder tumors [14]. In bladder transitional cell carcinomas, the expression level of VEGF-C is correlated with the pathological T stage of the tumor and with pelvic lymph node metastasis, venous involvement, and microvessel density [15]. Microvessel density is a key indicator of angiogenesis. Bladder cancer cells produce high levels of angiogenesis-stimulating factors, including VEGF, basic fibroblast growth factor (bFGF), and inflammatory cytokines required for vascular growth, such as interleukin (IL)-8 [16]. Hence, inhibiting the expression of these angiogenic factors in cancer cells will reduce tumor angiogenesis, thereby inhibiting tumor growth, progression, and metastasis.

Cortex Moutan, or the root bark of Paeonia suffruticosa Andrews, is viewed in traditional Chinese medicine as having bitter and slightly cold properties and being able to enter the heart, liver, and kidney meridians and dispel heat and blood stasis. Approximately 50 compounds have been identified in Cortex Moutan, including phenolic acids, tannins, and terpenes [17]. Cortex Moutan has been reported to have anti-inflammatory, antithrombotic, antiatherogenic, antitumor, immunomodulatory, and analgesic effects and to provide benefits to the circulatory, immune, and urogenital systems. Paeonol, a bioactive compound in Cortex Moutan, has been shown to exhibit antitumor activity in a mouse model of hepatoma established by injection of HepAhepatoma cells [18], as well as antiproliferative and apoptosis-inducing activities in human cancer cell lines, HT229 colon cancer cells [19] [20], HepG2 hepatocellular carcinoma cells [21], and SEG-1 and Eca-109 esophageal cancer cells [22]. A synthetic derivative of paeonol, paeonoloxime, has been shown to inhibit FGF-induced angiogenesis and reduce the levels of VEGF in HT1080 human fibrosarcoma cells [23]. Our current study has reported that Cortex Moutan exhibits antitumor activity in a mouse model of bladder cancer [24]. Other studies have also demonstrated various effects of Cortex Moutan in human cell lines: a methanol extract of Cortex Moutan lowered the expression levels of IL-8 through inhibiting the related inflammatory pathway in U937 monocytic cells [25]; an 
ethanol extract of Cortex Moutan induced apoptosis in AGS gastric cancer cells [26]; and an aqueous extract of Cortex Moutan inhibited the migration and metastasis of 786-O renal cell carcinoma cells via suppressing the VEGFR-3 signaling pathway [27]. In our previous research, an aqueous extract of Cortex Moutan inhibited the proliferation of human umbilical vein endothelial cells (HUVEC) and MCF-7 human breast cancer cells [28]. All of the above findings indicate that Cortex Moutan, either as a crude extract or as purified bioactive components thereof, possesses growth-inhibitory and apoptosis-inducing activities toward multiple types of cancer cells. Although our previous study has also demonstrated an inhibitory effect of aqueous Cortex Moutan extract on the growth of TSGH 8301 and BFTC 905 human bladder urothelial cancer cells [28], the cellular mechanisms involved have not been addressed. In this report, we present evidence that Cortex Moutan may be used as a therapeutic agent for bladder cancer, including Cortex Moutan's highly selective cytotoxic activity against cancer cells, ability to inhibit cell growth, arrest cell cycle progression, and induce cell death in bladder urothelial cancer cells, and inhibitory effect on the expression of angiogenic factors in those cells.

\section{Material and Methods}

\subsection{Validation of Cortex Moutan by HPLC Analysis}

Paeoniflorin and paeonol were purchased from Sigma Pharmaceutical Co. (Monticello, IA) for use as standards. The agents were accurately weighed and dissolved and serially diluted in $70 \%$ methanol to give concentrations of $150,75,37.5,18.75$, and $9.375 \mu \mathrm{g} / \mathrm{ml}$. Calibration curves were plotted following linear regression of the peak areas. Ten grams of Cortex Moutan (Sun Ten Pharmaceutical Co., Ltd., Taichung, Taiwan) was combined with $20 \mathrm{ml}$ of double-distilled water in a $50 \mathrm{ml}$ centrifuge tube and agitated at $4^{\circ} \mathrm{C}$ for $48 \mathrm{~h}$. The resulting solution was filtered using $0.22 \mu \mathrm{m}$ PVDF membrane, and the filtrate was freeze-dried to obtain $1.10 \mathrm{~g}$ of powder. The dried powder (46 mg) was combined with $1 \mathrm{ml}$ of $70 \%$ methanol and placed in an ultrasonic bath for $30 \mathrm{~min}$. Following centrifugation at $10,000 \mathrm{rpm}$ for $10 \mathrm{~min}$, the supernatant was filtered through a $0.45 \mu \mathrm{m}$ filter and analyzed by HPLC. The HPLC system (Agilent 1100) comprised a G1310A isocratic pump with solvent cabinet, aG1328A manual injector, a G1314A variable wavelength detector (VWD) with standard flow cell (10 mm path length, $14 \mu \mathrm{l}$ volume, 40-bar maximum pressure), and G2220AA 2D-Value Solution ChemStation software (Agilent Technologies, Waldbronn, Germany). The HPLC conditions for Cortex Moutan analysis were as follows. Analysis was performed with a ZORBAX Eclipse XDB-C8 column $(4.6 \times 150 \mathrm{~mm}, 5 \mu \mathrm{m}$, Supelco; Agilent Technologies). The mobile phase comprised $0.03 \%$ phosphate in water-acetonitrile $(0 \mathrm{~min}, 90: 10 ; 10 \mathrm{~min}$, 75:25; $20 \mathrm{~min}, 60: 40$; $30 \mathrm{~min}, 40: 60 ; 32 \mathrm{~min}, 85: 15 ; 35 \mathrm{~min}, 90: 10$ ). The flow rate was $0.6 \mathrm{ml} / \mathrm{min}$, and $10 \mu \mathrm{l}$ portions were injected into the column. The column temperature was set to $20^{\circ} \mathrm{C}$. The detector detected the compounds in Cortex Moutan at the wavelength of $230 \mathrm{~nm}$, and the retention times of paeoniflorin and paeonol were 11.6 and $27 \mathrm{~min}$, respectively.

\subsection{Preparation of Agents and Cell Cultures}

Cortex Moutan which was validated by HPLC was dissolved in double-distilled water and filtered using a 0.22micron filter. The concentration of the stock solution was thenconfirmed by weighing after lyophilization. Mitomycin C (Kyowa Hakko Kirin Co., Tokyo, Japan), doxorubicin (Actavis Italy S.P.A., Milan, Italy), and cisplatin (ABIC Biological Laboratories Ltd., Netanya, Israel) were dissolved in normal saline buffer at $1 \mathrm{mg} / \mathrm{ml}$ to provide stock solutions, which were then diluted with cell culture medium to desired concentrations ranging from 0.0025 to $0.08 \mathrm{mg} / \mathrm{ml}$. Human bladder papillary transitional cell line BFTC 905 and human bladder carcinoma cell line TSGH 8301 (Food Industry Research and Development Institute, Taiwan), as well asprimary normal human urothelial cell line HUC 4449 (ScienCell Research Laboratories, Carlsbad, CA), were used as cell models. BFTC 905 and TSGH 8301 cells were cultured in RPMI 1640 supplemented with $10 \%$ fetal bovine serum (FBS), 100 units/ml penicillin, and $100 \mu \mathrm{g} / \mathrm{ml}$ streptomycin. HUC 4449 cells were cultured in urothelial cell medium (ScienCell Research Laboratory, Carlsbad, CA) supplemented with 10\% FBS, 100 units/ml penicillin, and $100 \mu \mathrm{g} / \mathrm{ml}$ streptomycin. All cell lines were cultured at $37^{\circ} \mathrm{C}$ under a humidified atmosphere containing $5 \% \mathrm{CO}_{2}$, and all treatment with drugs was also performed under these conditions.

\subsection{Cell Viability Analysis}

To assess the cytotoxicity of Cortex Moutan, cell viability was determined with the use of Cell Counting Kit-8 
(CCK-8; Sigma-Aldrich Chemie GmbH, Steinheim, Germany). The reagent in the assay kit is converted by dehydrogenases in the mitochondria of live cells to generate a colored product that can be measured by absorbance at $450 / 650 \mathrm{~nm}$, allowing the absorbance reading to be directly correlated with the number of viable cells. This assay was therefore used to analyze the viability of Cortex Moutan-treated cells relative to that of control cells whose absorbance value was taken to be $100 \%$. The CCK-8 assay was performed as follows. BFTC 905 , TSGH 8301, and HUC 4449 cells were seeded in 96-well culture plates at $1 \times 10^{4}$ cells per well, cultured for $24 \mathrm{~h}$, and then washed with phosphate-buffered saline (PBS) and starved of serum by culturing in $100 \mu \mathrm{l}$ per well of culture medium without FBS for $24 \mathrm{~h}$. The culture medium was removed, and fresh medium containing Cortex Moutan, cisplatin, doxorubicin, or mitomycin $\mathrm{C}$ at various concentrations was added to the wells in triplicate and allowed to incubate with the cells for $24 \mathrm{~h}$. Cells in the control wells were incubated with fresh medium without drugs instead. Drug-treated and control cells were washed with PBS, and $10 \mu \mathrm{l}$ of CCK-8 reagent was added per well and incubated with the cells at $37^{\circ} \mathrm{C}$ and $5 \% \mathrm{CO}_{2}$ for $60 \mathrm{~min}$ before the culture plates were measured for absorbance at 450/650 nm in a microplate reader (Model 680; Bio-Rad, Hercules, CA). For each drug, cell viability at each drug concentration was calculated as follows:

$$
\text { Viability }=\text { absorbance of treated cells/absorbance of control cells } \times 100 \%
$$

The viability values were plotted against drug concentration, and the drug concentration at which $50 \%$ of the treated cells were nonviable (IC50) was estimated from the data. To estimate the IC50 we plotted x-y and fitted the data with a straight line (linear regression). IC50 value was then estimated using the fitted line, i.e.,

$$
\begin{aligned}
& \mathrm{Y}=\mathrm{a} * \mathrm{X}+\mathrm{b}, \\
& \mathrm{IC} 50=(0.5-\mathrm{b}) / \mathrm{a} .
\end{aligned}
$$

In addition, the selectivity index (SI) of each drug, representing the cytotoxic selectivity of the drug against cancer cells relative to normal cells, was calculated as follows:

$$
\mathrm{SI}=\mathrm{IC}_{50} \text { of drug in normal cells } / \mathrm{IC}_{50} \text { of drug in cancer cells }
$$

\subsection{Cell Cycle Analysis}

Bladder cancer cells were seeded in 6-well culture plates at $1-2 \times 10^{5}$ cells per well and cultured for $24 \mathrm{~h}$, starved for serum in $2 \mathrm{ml}$ per well of culture medium without FBS for $24 \mathrm{~h}$, and then treated in triplicate with Cortex Moutan at various concentrations in culture medium for $24 \mathrm{~h}$. Afterwards, the cells were completely dissociated by treatment with trypsin-EDTA, which was directly added at $2 \mathrm{X}$ concentration at $2 \mathrm{ml}$ per well, and the cells were then dehydrated and fixed as single-cell suspensions in methanol at $2 \mathrm{ml}$ per well at $4{ }^{\circ} \mathrm{C}$ for $24 \mathrm{~h}$. The fixed cells were collected by centrifugation at $1500 \mathrm{rpm}$ for $10 \mathrm{~min}$, rehydrated and washed with ice-cold PBS, and stained by incubating with $10 \mathrm{mg} / \mathrm{ml}$ RNase A and $1 \mathrm{mg} / \mathrm{mlpropidium} \mathrm{iodide} \mathrm{in} \mathrm{PBS} \mathrm{in} \mathrm{the} \mathrm{dark} \mathrm{at}$ room temperature for 30 min before being subjected to flow cytometry analysis for cell cycle status. Ten thousand cells of each sample type were collected for the analysis.

\subsection{Apoptosis Analysis}

Bladder cancer cells were cultured for $24 \mathrm{~h}$ and treated in triplicate with various concentrations of Cortex Moutan for $24 \mathrm{~h}$ as described above and then dissociated to single cells with Trypsin-EDTA, directly added at 2X concentration at $1 \mathrm{ml}$ per well of 6-well plates. By using components of the Annexin V-FITC Apoptosis Detection Kit (BioVision, Mountain View, CA), the trypsinized cells harvested from each well were resuspended in $500 \mu \mathrm{l}$ of binding buffer, mixed with $5 \mu \mathrm{l}$ of annexin V-FITC and $5 \mu \mathrm{l}$ of $50 \mathrm{ug} / \mathrm{mlpropidium} \mathrm{iodide} \mathrm{(optional),}$ and allowed to incubate in the dark for 5 min before being subjected to flow cytometry analysis to detect apoptotic cells. Ten thousand cells of each sample type were collected for the analysis.

\subsection{Protein Analysis by Western Blotting}

Bladder cancer cells (BFTC 905 and TSGH 8301) were seeded in 6-well culture plates at $1-2 \times 10^{5}$ cells per well and cultured for $24 \mathrm{~h}$, starved for serum in $2 \mathrm{ml}$ per well of culture medium without FBS for $24 \mathrm{~h}$, and then treated with $1 \mathrm{mg} / \mathrm{ml}$ Cortex Moutan in culture medium for 16 or $24 \mathrm{~h}$. Cell total proteins were extracted from 
the treated cells and identified using a Bio-Rad protein assay (Bio-Rad, Hercules, CA) with bovine serum albumin (BSA) as a standard. Each lysate $(10 \mu \mathrm{g})$ was resolved on denaturing polyacrylamide gels and transferred electrophoretically to a PVDF transfer membrane. The membranes were blocked with blocking buffer (Bio-Rad, Hercules, CA) for $1 \mathrm{~h}$, incubated with primary antibodies at $4^{\circ} \mathrm{C}$ overnight, and then incubated with horseradish peroxidase-conjugated secondary antibodies at room temperature for $1 \mathrm{~h}$, with membrane washing carried out after each of the steps in TBST buffer. Antibody-bound proteins on the blots were detected with ECL Western Blotting Detection Reagents (GE Healthcare Biosciences, Piscataway, NJ), followed by chemiluminescent imaging using the BioSpectrum 800 system (UVP, Upland, CA).

\subsection{Statistical Analysis}

Analysis of cell viability, cell cycle, or apoptosis at each drug concentration was performed with triplicate samples. Data are expressed relative to no-treatment controls as mean \pm standard deviation (SD). The significance of differences between drug treatments was analyzed by one-way ANOVA followed by Dunnett's post hoc test for multiple comparisons. A $P$-value $<0.01$ was regarded as statistically significant.

\section{Results}

\subsection{HPLC Analysis of Cortex Moutan}

The bioactive components of Cortex Moutan are paeoniflorin and paeonol. The distinctly different structures of these two compounds produced different solubility properties, which led to different HPLC retention times as detected at the $230 \mathrm{~nm}$ absorption wavelength. We ran calibration standards containing paeoniflorin and paeonol and found the retention times to be 11.6 and 27 min, respectively (Figure 1). Accordingly, we used the identical HPLC method to determine the presence of paeoniflorin and paeonol in our Cortex Moutan sample by retention time. As shown in Figure 2, the chromatogram displays a peak at $11.6 \mathrm{~min}$ and at $27 \mathrm{~min}$, indicating that the Cortex Moutan sample contained both paeoniflorin and paeonol analytes.

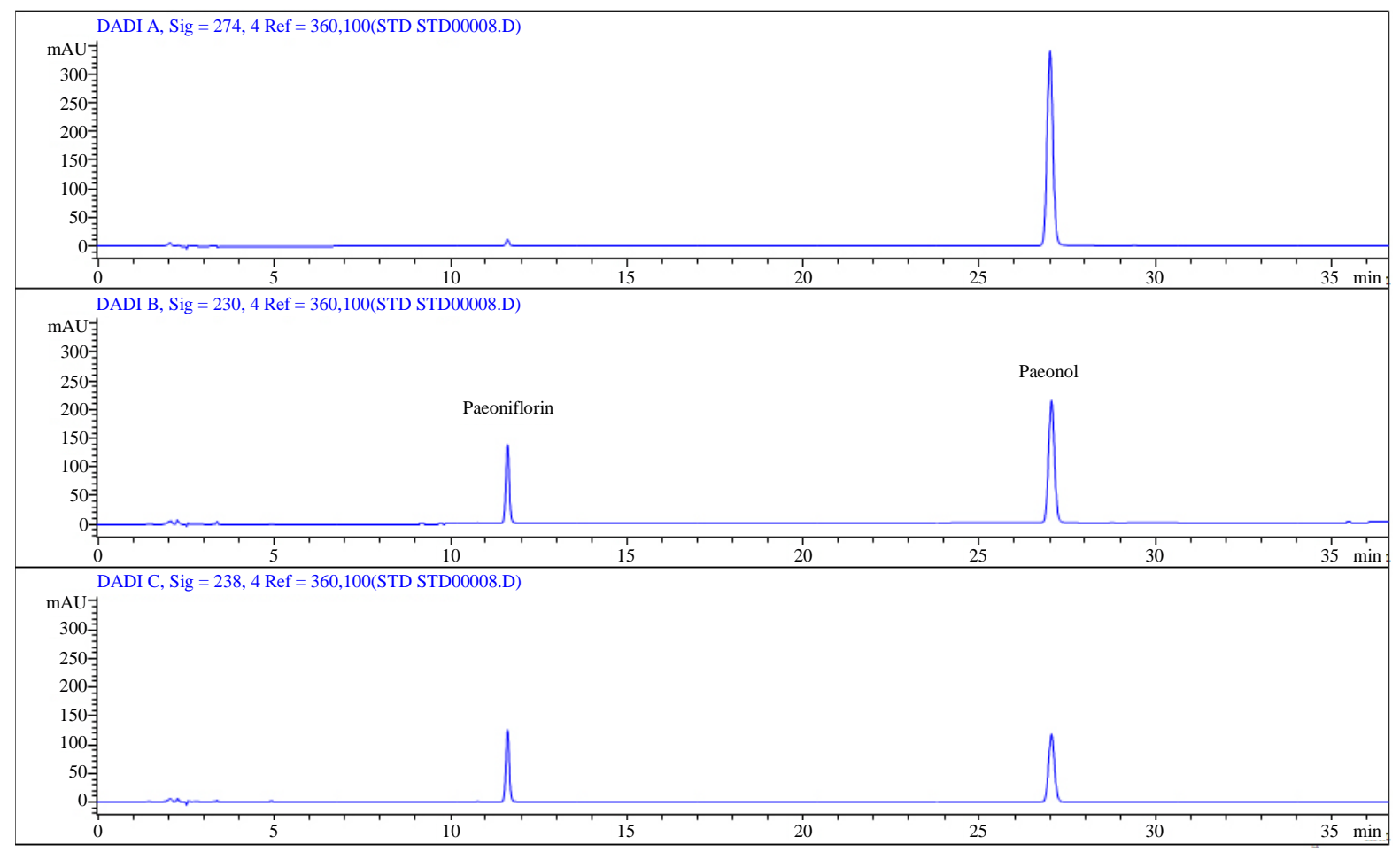

Figure 1. HPLC profiles of paeoniflorin and paeonol standards at three detection wavelengths. Chromatograms are shown for detection at $274 \mathrm{~nm}$ (top panel), $230 \mathrm{~nm}$ (middle), and $238 \mathrm{~nm}$ (bottom). Paeoniflorin was detected at $11.6 \mathrm{~min}$; paeonol, at $27 \mathrm{~min}$. Based on these profiles, $230 \mathrm{~nm}$ was selected as the detection wavelength for subsequent qualitative and quantitative HPLC analysis. 


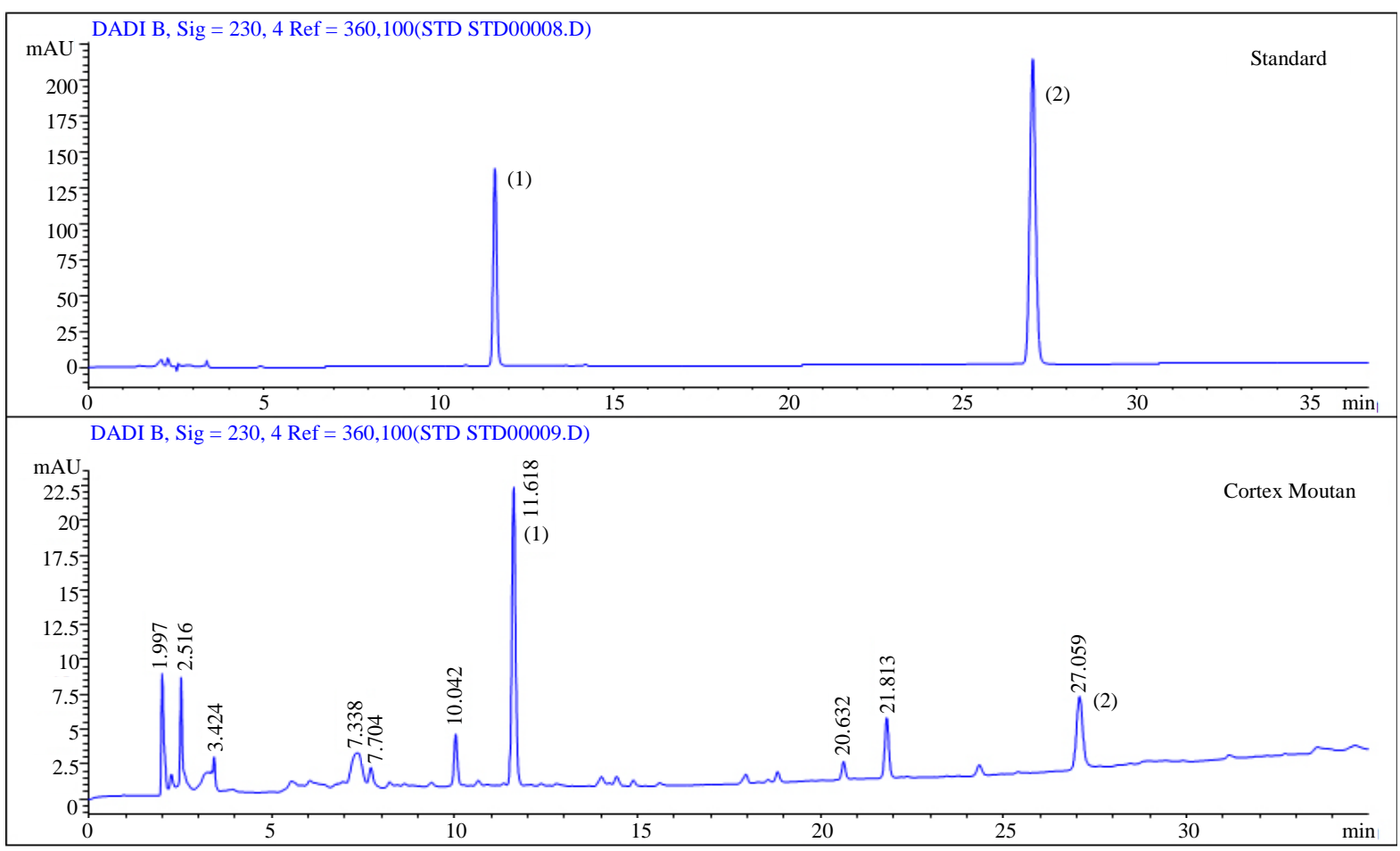

Figure 2. HPLC-UV analysis of Cortex Moutan. Standards containing the target analytes, paeoniflorin (peak 1; retention time, $11.6 \mathrm{~min}$ ) and paeonol (peak 2; retention time, $27 \mathrm{~min}$ ), were used to calibrate the HPLC instrument. Both analytes were among the main compounds detected in the Cortex Moutan sample.

\subsection{Cortex Moutan Exhibits Cytotoxicity against Human Bladder Cancer Cell Lines and Has Lower Cytotoxicity toward Normal Urothelial Cells}

To examine the cytotoxic activity of Cortex Moutan, we cultured two human bladder cancer cell lines in the presence of various concentrations of Cortex Moutan for $24 \mathrm{~h}$ and then analyze the viability of the cells by performing the CCK-8 assay. The results showed that the viability of human bladder cancer cells decreased with increasing concentration of Cortex Moutan (Figure 3). Cortex Moutan treatment reduced cell viability by as much as 74\% and 82\% in BFTC 905 and TSGF 8301 cells, respectively (Figure 3), and the Cortex Moutan concentration that corresponded to a $50 \%$ reduction in cell viability $\left(\mathrm{IC}_{50}\right)$ was 0.4633 and $0.5782 \mathrm{mg} / \mathrm{ml}$, respectively. IC I0 $_{50}$ values in BFTC 905 and TSGH 8301 cells were also determined for three common chemotherapeutic agents, cisplatin $(0.044$ and $0.0041 \mathrm{mg} / \mathrm{ml}$, respectively), doxorubicin $(0.0021$ and $0.0019 \mathrm{mg} / \mathrm{ml})$, and mitomycin C $(0.0041$ and $0.004 \mathrm{mg} / \mathrm{ml})$ (Table 1$)$. In order to test the cytotoxicity of Cortex Moutan in human urothelial cells, the same drug treatments and viability analysis were performed with primary normal human urothelial cells of the HUC 4449 line. We found that the viability of HUC 4449 cells were not significantly affected by treatment with Cortex Moutan at concentrations up to $1 \mathrm{mg} / \mathrm{ml}$, but a reduced viability was observed at $2 \mathrm{mg} / \mathrm{ml}$ (Figure 3), giving an $\mathrm{IC}_{50}$ value of $2.81 \mathrm{mg} / \mathrm{ml}$ (Table 1). In contrast, cisplatin, doxorubicin, and mitomycin C significantly reduced the viability of HUC 4449 cells at much lower concentrations and had respective $\mathrm{IC}_{50}$ values of $0.0232,0.0054$, and $0.0102 \mathrm{mg} / \mathrm{ml}$ (Table 1 ). Taken together, the above data show that Cortex Moutan exhibited cytotoxic activity against human bladder cancer cell lines while being substantially less cytotoxic toward normal urothelial (HUC 4449) cells than mitomycin C, doxorubicin, and cisplatin.

\subsection{Cortex Moutan Exhibits Greater Selective Cytotoxicity against Bladder Cancer Cells than Mitomycin C, Doxorubicin, and Cisplatin}

To assess the selectivity of Cortex Moutan's cytotoxicity against cancer cells rather than normal cells, we calculated the selectivity index (SI) of each drug for BFTC 905 and TSGH 8301 cells. The SI is defined as the ratio between the $\mathrm{IC}_{50}$ in normal cells and the $\mathrm{IC}_{50}$ in cancer cells for a given drug. A drug with a larger selectivity 


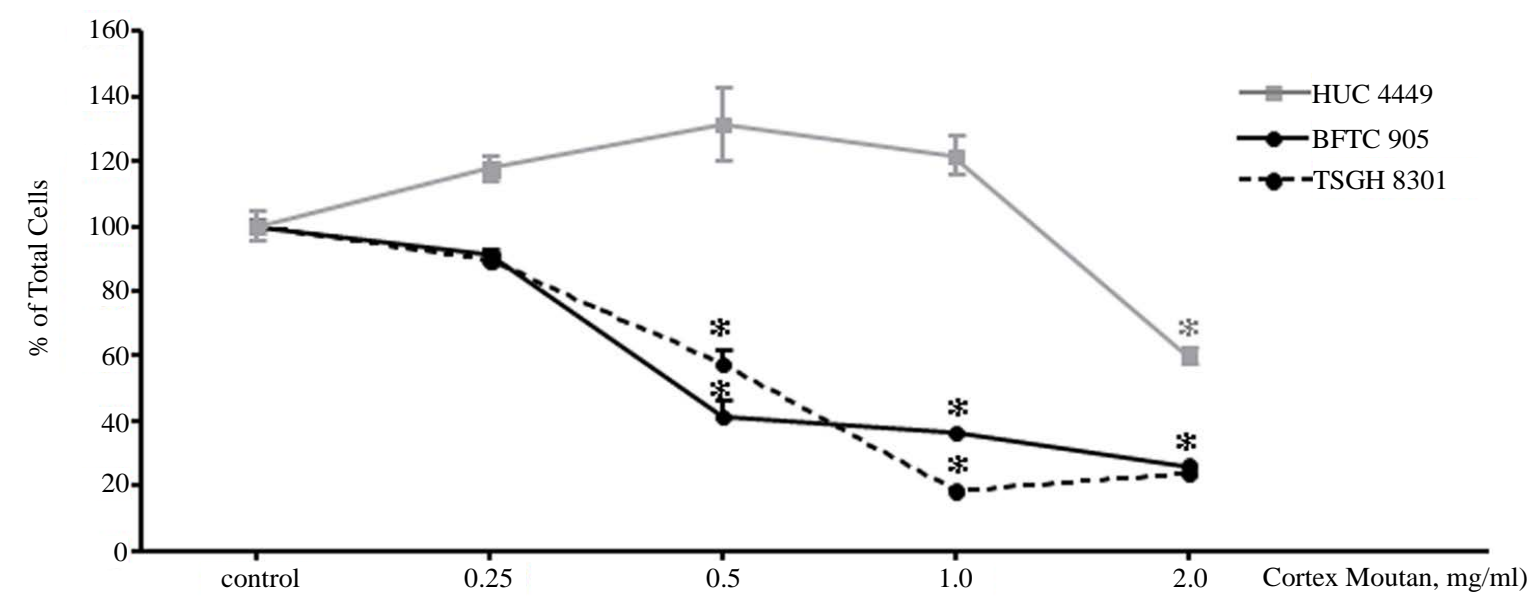

Figure 3. Effect of Cortex Moutan on cell viability. The CCK-8 assay was used to analyze the viability of normal human urothelial cells (HUC 4449) and human bladder cancer cells (BFTC 905 and TSGH 8301) after 24 h of exposure to various concentrations of Cortex Moutan. Each viability value represents the mean \pm SD of three replicates. An asterisk (*) at a given drug concentration denotes a significant difference $(P<0.01)$ from the no-treatment control.

Table 1. IC $_{50}$ values of Cortex Moutan, mitomycin C, doxorubicin, and cisplatin in normal human urothelial cells (HUC 4449) and human bladder cancer cell lines TSGH 8301 and BFTC 905.

\begin{tabular}{cccc}
\hline \multicolumn{3}{c}{ IC $\left._{\mathbf{5 0}} \mathbf{( m g / m l}\right) *$} \\
\hline HUC 4449 & TSGH 8301 & BFTC 905 \\
\hline Cortex Moutan & $2.810 \pm 0.2698$ & $0.5782 \pm 0.0727$ & $0.4633 \pm 0.1030$ \\
Cisplatin & $0.0232 \pm 0.0069$ & $0.0041 \pm 0.0013$ & $0.0440 \pm 0.0020$ \\
Doxorubicin & $0.0054 \pm 0.001$ & $0.0019 \pm 0.0002$ & $0.0021 \pm 0.0001$ \\
Mitomycin-C & $0.0102 \pm 0.002$ & $0.0040 \pm 0.0005$ & $0.0041 \pm 0.0002$ \\
\hline
\end{tabular}

${ }^{*}$ Drug concentration at which $50 \%$ of the treated cells are nonviable relative to untreated cells. Data are shown as mean \pm SD of three replicates.

index would exert a more potent cytotoxic effect on cancer cells with less cytotoxicity to normal cells, and thus has more selective cytotoxicity toward cancer cells. We found the SI values of Cortex Moutan for BFTC 905 and TSGH 8301 cells to be 6.30 and 5.05, respectively (Table 2), both far greater than 3, indicating Cortex Moutan's highly selective cytotoxicity toward cancer cells [29]. In contrast, the SI values of mitomycin C, doxorubicin, and cisplatin for BFTC 905 cells and of doxorubicin and mitomycin C for TSGH 8301 cells were all less than 3 (Table 2), indicating these drugs' relatively low selective cytotoxicity toward cancer cells. These results demonstrate that relative to mitomycin C, doxorubicin, and cisplatin, Cortex Moutan more effectively inhibited the growth of BFTC 905 and TSGH 8301 human bladder cancer cells under conditions that preserved the viability of normal cells.

\subsection{Cortex Moutan Induces Cell Cycle Arrest in Bladder Cancer Cells}

Next, we examined the effect of Cortex Moutan on cell cycle progression in human bladder cancer cells. As shown by the results of flow cytometry analysis, treatment with Cortex Moutan at $0.25,0.5$, or $0.75 \mathrm{mg} / \mathrm{ml}$ significantly decreased the proportion of BFTC 905 cells in the G0/G1 phase and increased the proportion in the $\mathrm{S}$ phase (Figure 4(a)). In identically treated TSGH 8301 cells, the proportion in the G0/G1 phase also significantly decreased, but the proportion in the G2/M phase significantly increased (Figure 4(b)). These results indicate that Cortex Moutan induced cell cycle arrest in BFTC 905 cells at the G1/S transition, as well as in TSGH 8301 cells at the G2/M transition. Also, we observed marked increases in the sub-G1 populations of BFTC 905 and TSGH 8301 cells treated with 0.5 or $0.75 \mathrm{mg} / \mathrm{ml}$ Cortex Moutan (Figure 4), suggesting that Cortex Moutan induced cell damage in these cell lines, resulting in an increased occurrence of DNA aneuploidy and cell death.

\subsection{Cortex Induces Cell Death in Bladder Cancer Cells}

As a number of studies have shown that arrested cell cycle progression may cause cells to undergo apoptosis [30] 
Table 2. Cytotoxicity selectivity indexes of Cortex Moutan, mitomycin C, doxorubicin, and cisplatin for human bladder cancer cell lines TSGH 8301 and BFTC 905.

\begin{tabular}{ccc}
\hline & Selectivity index (SI)* & \\
\hline & TSGH 8301 & BFTC 905 \\
\hline Cortex Moutan & 5.05 & 6.30 \\
Cisplatin & 5.66 & 0.52 \\
Doxorubicin & 2.84 & 2.57 \\
Mitomycin C & 2.55 & 2.49 \\
\hline
\end{tabular}

${ }^{*}$ A value $>3$ indicates high selectivity.
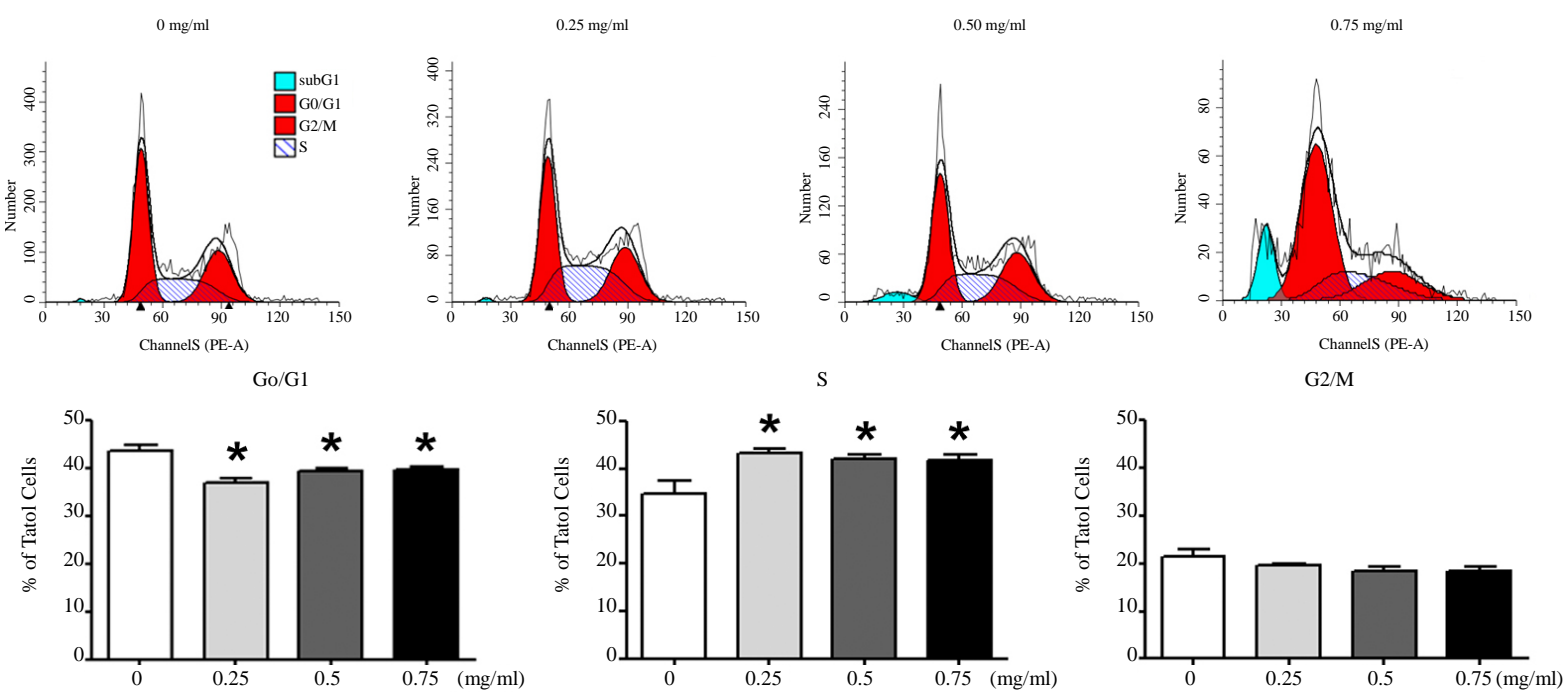

(a)
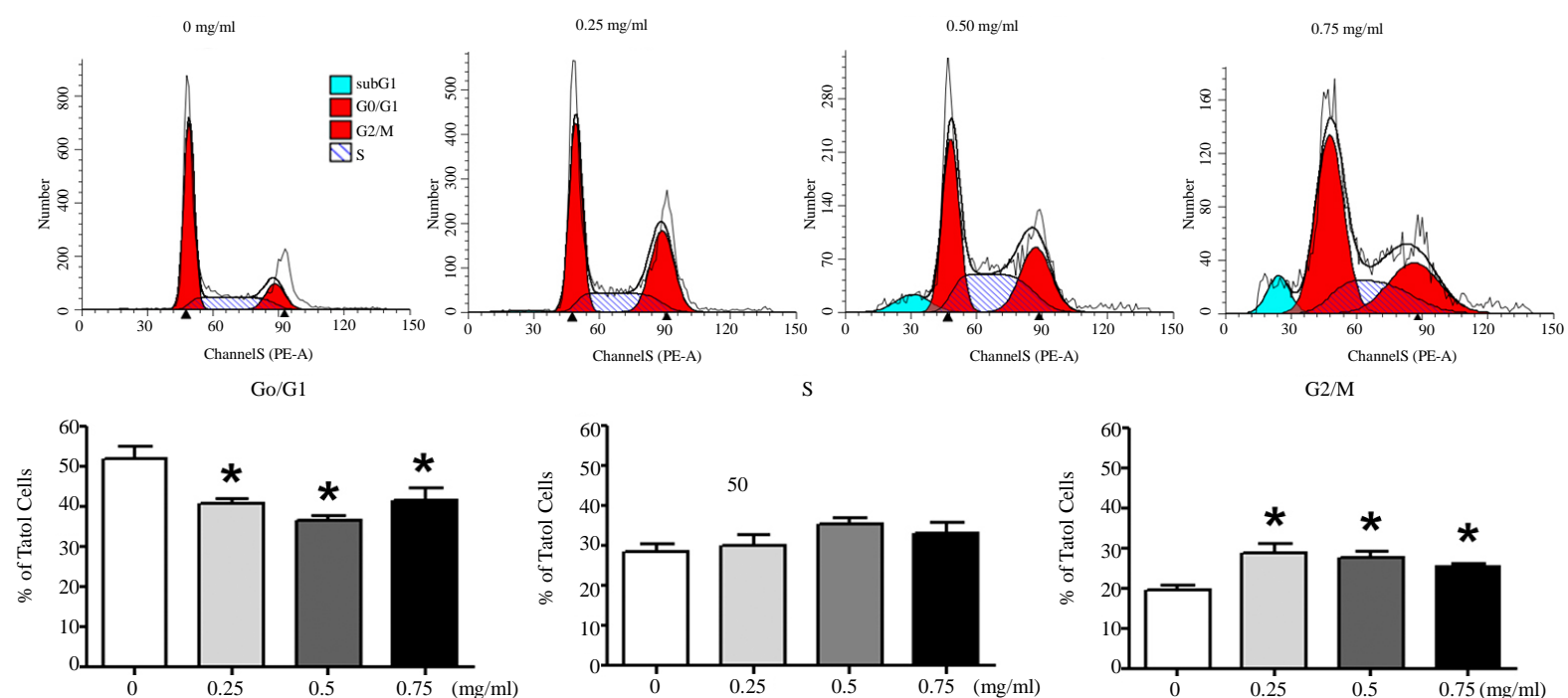

(b)

Figure 4. Effect of Cortex Moutan on cell cycle progression in human bladder cancer cells. BFTC 905 (a) and TSGH 8301 (b) cells were treated with $0.25,0.5$, or $0.75 \mathrm{mg} / \mathrm{ml}$ Cortex Moutan for $24 \mathrm{~h}$, stained with propidium iodide, and analyzed by flow cytometry to determine the percentages of cells in different phases of the cell cycle. Each percentage represents the mean \pm SD of three replicates. An asterisk $(*)$ at a given drug concentration denotes a significant difference $(P<0.01)$ from the no-treatment control. 
[31], we wished to ascertain whether the Cortex Moutan—induced cell death observed was mainly due to apoptosis or necrosis. Through flow cytometry analysis, we found that nearly $7.5 \%$ of BFTC 905 cells were apoptotic in the absence of Cortex Moutan, and treatment with Cortex Moutan at $0.75 \mathrm{mg} / \mathrm{ml}$ significantly increased the percentages of both apoptotic cells and necrotic cells (Figure 5(a)). In TSGH 8301 cells, Cortex Moutan treatment induced primarily apoptotic death and secondarily necrotic death, both in a dose-dependent manner (Figure 5(b)). These results show that Cortex Moutan induced both apoptotic and necrotic death in bladder cancer cells,
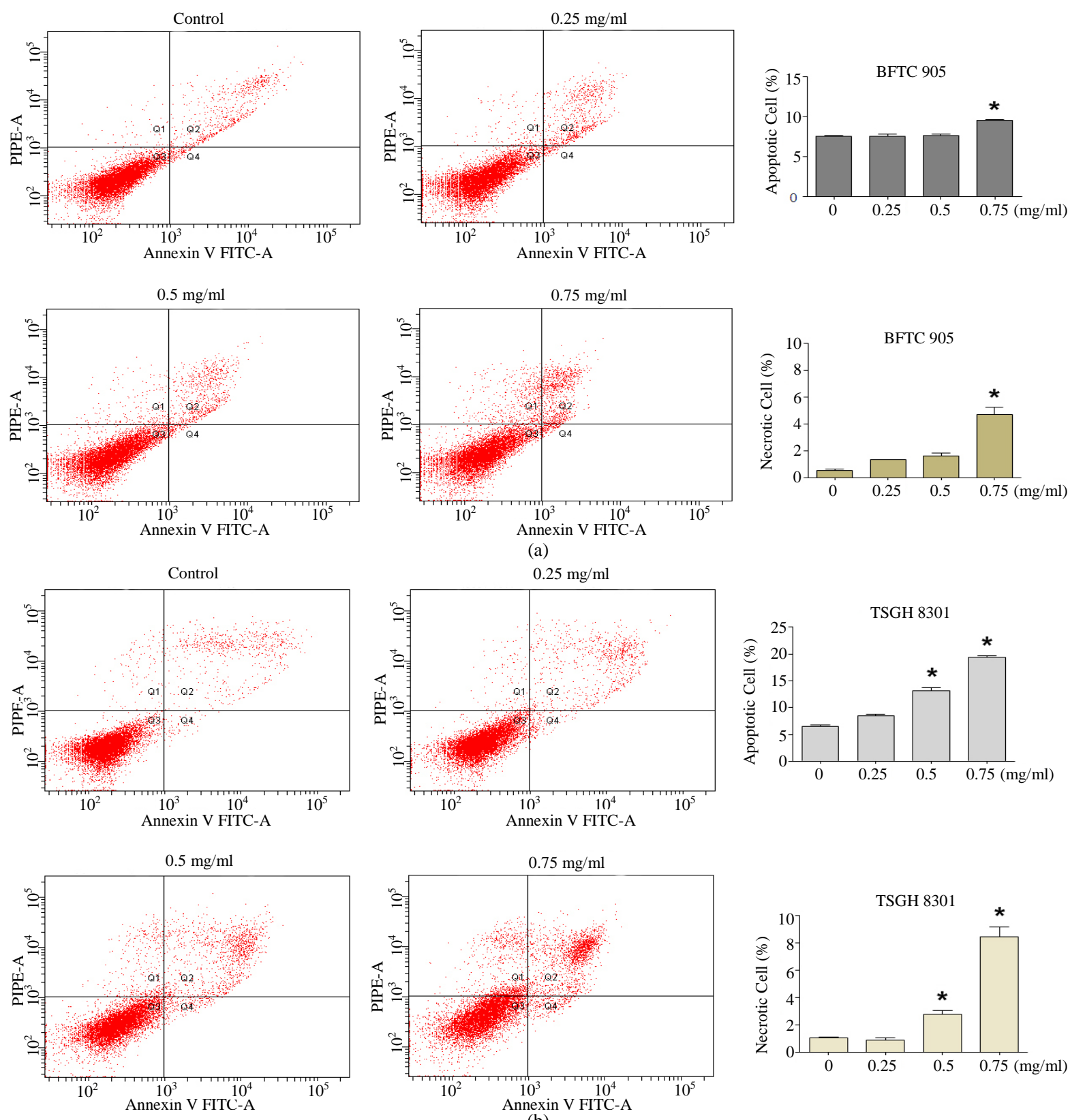

Figure 5. Effect of Cortex Moutan on cell death in human bladder cancer cells. BFTC 905 (a) and TSGH 8301 (b) cells were treated with $0.25,0.5$, or $0.75 \mathrm{mg} / \mathrm{ml}$ Cortex Moutan for $24 \mathrm{~h}$, stained with annexin V and propidium iodide (PI), and analyzed by flow cytometry to determine the relative percentages of apoptotic and necrotic cells. The lower left quadrant (Q3) represents viable cells; the upper left quadrant (Q1), necrotic cells; the lower right quadrant (Q4), early apoptotic cells; and the upper right quadrant (Q2), late apoptotic cells. The relative percentages of apoptotic cells_including both early and late apoptotic cells-and of necrotic cells were determined. The data are expressed as the means \pm SD of three replicates. An asterisk $(*)$ denotes a significant difference $(P<0.01)$ from the no-treatment control. 
with different cancer cell lines exhibiting different sensitivities to the cell death—inducing effects of Cortex Moutan treatment.

\subsection{Cortex Moutan Inhibits the Protein Expression of Angiogenic Factors}

In tumor angiogenesis, angiogenic factors such as bFGF, VEGF, and IL-8 are produced by cancer cells to stimulate the formation of new blood vessels. Thus, inhibiting cancer cells' expression of these angiogenic factors will decrease vascular growth, thereby inhibiting tumor growth, progression, and metastasis. We therefore further examined the effect of Cortex Moutan on the protein expression of bFGF, VEGF, and IL-8 in bladder cancer cells. As detected by western blot analysis, treatment with Cortex Moutan at $1 \mathrm{mg} / \mathrm{ml}$ for 16 or $24 \mathrm{~h}$ significantly decreased the level of VEGF in BFTC 905 and TSGH 8301 cells (Figure 6(b)).However, we detected a mild decrease in the levels of bFGF and IL-8 in BFTC 905 and TSGH 8301 cells (Figure 6(a) \& Figure 6(c)). These results show that Cortex Moutan inhibited the protein expression of VEGF and slightly decreased the protein expression of bFGF and IL-8 in cancer cells.

\section{Discussion}

Research on the anticancer properties of Cortex Moutan has been gaining interest in recent years, with many published reports describing Cortex Moutan's antiproliferative effects on human cancer cell lines encompassing such common malignancies as breast ductal carcinoma, colon cancer, hepatocellular carcinoma, gastric cancer, and esophageal cancer [18]-[22] [32]. Our present report shows that Cortex Moutan exerts a dose-dependent cytotoxic effect on bladder cancer cells, which is consistent with our previous finding that aqueous Cortex Moutan extract inhibited the growth of TSGH 8301 and BFTC 905 human bladder cancer cell lines with respective IC50 values of 0.33 and $0.14 \mathrm{mg} / \mathrm{ml}$ [28]. Of particular importance is our current finding that Cortex Moutan significantly inhibited bladder cancer cell growth at concentrations that did not significantly affect the viability of normal human urothelial cells (Figure 3). In addition, we compared the anticancer activity of Cortex Moutan with those of three intravesical chemotherapeutic drugs currently in clinical use in Taiwan, and found that Cortex Moutan not only displayed similar cytotoxic activity against bladder cancer cells but also had lower cytotoxicity toward normal cells than did those drugs. This was demonstrated through assessing the selectivity indexes (SIs) of the drugs for human bladder cancer cell lines. Each SI value represents the potency of the drug's antitumor cytotoxicity under conditions that avoid cytotoxicity to normal cells, namely, the drug's selective antitumor cytotoxicity, with an SI value greater than 3 indicating highly selective cytotoxicity against cancer cells [29]. As revealed by our results (Table 2), Cortex Moutan was highly selectively cytotoxic toward both BFTC 905 and TSGH 8301 cells (SI values, 6.30 and 5.05, respectively); in contrast, cisplatin was highly selective toward only one of the bladder cancer cell lines (TSGH 8301; SI, 5.66), and mitomycin C and doxorubicin had poorly selective cytotoxicity toward both cell lines (SI values < 3) [29]. Therefore, we conclude that Cortex Moutan has higher anticancer activity than mitomycin C, doxorubicin, or cisplatin. It is noteworthy that the IC50 and SI values for cisplatin differed significantly between the two human bladder cancer cell lines (Table 1 and Table 2).

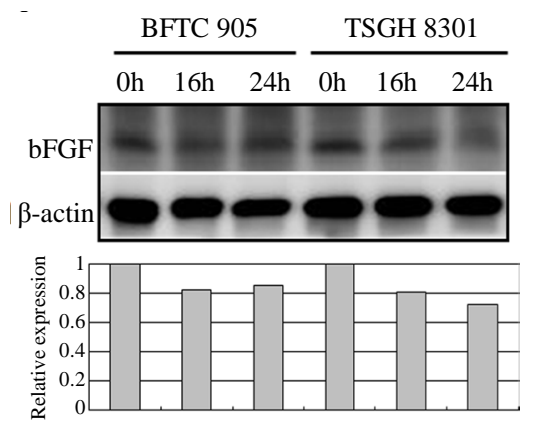

(a)

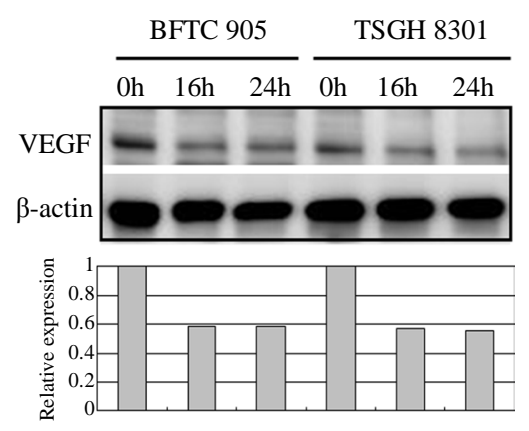

(b)

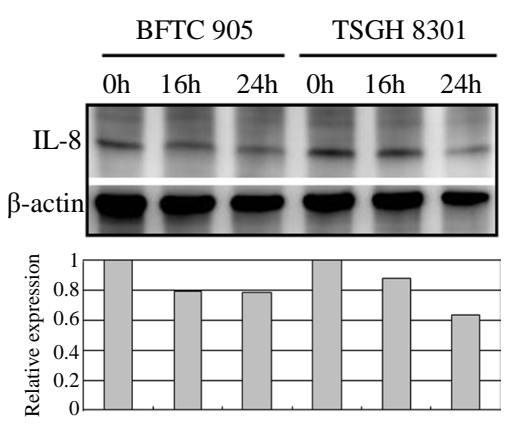

(c)

Figure 6. Effect of Cortex Moutan on protein expression of three angiogenic factors in human bladder cancer cells. BFTC 905 and TSGH 8301 cells were treated with $1 \mathrm{mg} / \mathrm{ml}$ Cortex Moutan for 16 or $24 \mathrm{~h}$ and then analyzed for bFGF (a), VEGF (b), and IL-8 (c) by western blotting, with $\beta$-actin blots serving as internal controls. Protein expression was quantified relative to that of control cells at $0 \mathrm{~h}$ and was presented as relative expression in bar graphs. 
That is, BFTC 905 cells were much more resistant than TSGH 8301 cells to the cytotoxic effects of cisplatin. The underlying mechanism for this resistance is not clear, but a study has shown that the greater cisplatin resistance of the non-small cell (large-cell) lung cancer cell line H460 is related to a high expression level of $\mathrm{X}$-linked inhibitor of apoptosis protein (XIAP) [33]. Further research is needed to clarify the mechanism of cancer cell resistance to cisplatin.

We also performed flow cytometry analysis to characterize the specific cellular effects of Cortex Moutan on human bladder cancer cells, including cell cycle changes, apoptosis, and necrosis. As BFTC 905 cells originated from a female grade 3/stage C bladder carcinoma and TSGH 8301 cells were derived from a male grade 2/stage A bladder carcinoma, these cell lines would be expected to differ in a number of characteristics, and they in fact gave somewhat different results in our analysis. We found that Cortex Moutan induced arrest of cell cycle progression at the G1/S transition in BFTC 905 cells and at the G2/M transition in TSGH 8301 cells (Figure 4). A recent study observed similar patterns of cell cycle arrest in BFTC 905 and TSGH 8301 cells that were treated with a traditional Chinese medicine formula, Guizhi Fuling Wan [34], raising the possibility that any particular bladder cancer cell line may respond to unfavorable environmental conditions (such as the presence of drugs) by preferentially activating specific mechanisms of arresting cell cycle progression; this idea remains to be tested. Because cell cycle arrest may sometimes lead to apoptosis, we also investigated whether Cortex Moutan can induce apoptosis in bladder cancer cells. We found that Cortex Moutan induced both apoptosis and necrosis in a dose-dependent manner in TSGH 8301 cells (Figure 5(b)), but BFTC 905 cells were less responsive to the cell death-inducing effects Cortex Moutan, exhibiting significantly increased apoptosis and necrosis only at a higher dosage $(0.75 \mathrm{mg} / \mathrm{ml}$ ) (Figure $5(\mathrm{a}))$. Our combined results from cell cycle and cell death analyses suggest that Cortex Moutan may exert its cytotoxic effect on bladder cancer cells primarily through the induction of the apoptosis program and secondarily through the induction of necrotic processes.

Generally, as a tumor continues to grow and its demand for nutrients outstrips the supply from the existing vasculature, the tumor cells will produce and release angiogenesis-promoting factors such as bFGF, VEGF, and IL-8 [35] [36] to induce the growth of new blood vessels toward the tumor. In addition, the tumor cells can gain entry into the circulatory system through the new vessels and thereby invade other tissues and organs [37]. If the production of angiogenic factors in tumor cells can be blocked, then tumor growth and metastasis can be effectively suppressed. On the basis of previous research [23] [25] [27], we expected that Cortex Moutan would inhibit the protein expression of angiogenic factors in bladder cancer cells, and it did. The levels of VEGF, bFGF, and IL-8 in BFTC 905 and TSGH 8301 cells all decreased by 20\% - 40\% after 16 or $24 \mathrm{~h}$ of treatment with Cortex Moutan (Figure 6), suggesting Cortex Moutan's potential to suppress bladder tumor angiogenesis.

\section{Conclusion}

Collectively, the results from our present study show that Cortex Moutan has dose-dependent anticancer effects on bladder cancer cells. Importantly, Cortex Moutan effectively induces cytotoxicity in bladder cancer cells at dosages that cause no significant cytotoxicity to normal human urothelial cells. Furthermore, we have identified specific cellular effects of Cortex Moutan in bladder cancer cells, including induction of cell cycle arrest, increased cell death in the forms of apoptosis and necrosis, and reduced protein expression of angiogenic factors. As the present study represents the initial, cell culture analysis phase of research, the anticancer activity and low toxic side effects of Cortex Moutan should be confirmed and further evaluated in a mouse model of bladder carcinoma in situ using Cortex Moutan as an intravesical treatment.

\section{Acknowledgements}

The author(s) disclosed receipt of the following financial supportfor the research and/or authorship of this article. This study was supported by the Chia-Yi Christian Hospital (Grant R100-2).

\section{References}

[1] Oosterlinck, W., Solsona, E., van der Meijden, A.P., Sylvester, R., Bohle, A., Rintala, E. and Lobel, B. (2004) EAU Guidelines on Diagnosis and Treatment of Upper Urinary Tract Transitional Cell Carcinoma. European Urology, 46, 147-154. http://dx.doi.org/10.1016/j.eururo.2004.04.011

[2] Heney, N.M. (1992) Natural History of Superficial Bladder Cancer. Prognostic Features and Long-Term Disease Course. Urologic Clinics of North America, 19, 429-433. 
[3] Roupret, M., Zigeuner, R., Palou, J., Boehle, A., Kaasinen, E., Sylvester, R., Babjuk, M. and Oosterlinck, W. (2012) European Guidelines for the Diagnosis and Management of Upper Urinary Tract Urothelial Cell Carcinomas: 2011 Update. Actas Urológicas Españolas, 36, 2-14. http://dx.doi.org/10.1016/j.acuro.2011.09.001

[4] Lower Jr., G.M. (1982) Concepts in Causality: Chemically Induced Human Urinary Bladder Cancer. Cancer, 49, 10561066. http://dx.doi.org/10.1002/1097-0142(19820301)49:5<1056::AID-CNCR2820490535>3.0.CO;2-I

[5] Burger, M.S., Torino, J.L. and Swaminathan, S. (2001) DNA Damage in Human Transitional Cell Carcinoma Cells after Exposure to the Proximate Metabolite of the Bladder Carcinogen 4-Aminobiphenyl. Environmental and Molecular Mutagenesis, 38, 1-11. http://dx.doi.org/10.1002/em.1044

[6] Tan, L.B., Chen, K.T. and Guo, H.R. (2008) Clinical and Epidemiological Features of Patients with Genitourinary Tract Tumour in a Blackfoot Disease Endemic Area of Taiwan. BJU International, 102, 48-54. http://dx.doi.org/10.1111/j.1464-410X.2008.07565.x

[7] Yang, C.Y., Chiu, H.F., Chang, C.C., Ho, S.C. and Wu, T.N. (2005) Bladder Cancer Mortality Reduction after Installation of a Tap-Water Supply System in an Arsenious-Endemic Area in Southwestern Taiwan. Environmental Research, 98, 127-132. http://dx.doi.org/10.1016/j.envres.2004.07.013

[8] Wallerand, H., Bakkar, A.A., de Medina, S.G., Pairon, J.C., Yang, Y.C., Vordos, D., Bittard, H., Fauconnet, S., Kouyoumdjian, J.C., Jaurand, M.C., et al. (2005) Mutations in TP53, but Not FGFR3, in Urothelial Cell Carcinoma of the Bladder Are Influenced by Smoking: Contribution of Exogenous Versus Endogenous Carcinogens. Carcinogenesis, 26, 177-184. http://dx.doi.org/10.1093/carcin/bgh275

[9] Spiess, P.E. and Czerniak, B. (2006) Dual-Track Pathway of Bladder Carcinogenesis: Practical Implications. Archives of Pathology \& Laboratory Medicine, 130, 844-852.

[10] Barocas, D.A. and Clark, P.E. (2008) Bladder Cancer. Current Opinion in Oncology, 20, 307-314. http://dx.doi.org/10.1097/CCO.0b013e3282f8b03e

[11] Chen, C.H., Yang, H.J., Shun, C.T., Huang, C.Y., Huang, K.H., Yu, H.J. and Pu, Y.S. (2010) A Cocktail Regimen of Intravesicalmitomycin-C, Doxorubicin, and Cisplatin (MDP) for Non-Muscle-Invasive Bladder Cancer. Urologic Oncology, 30, 421-427. http://dx.doi.org/10.1016/j.urolonc.2010.06.012

[12] Afonso, J., Santos, L.L., Amaro, T., Lobo, F. and Longatto-Filho, A. (2009) The Aggressiveness of Urothelial Carcinoma Depends to a Large Extent on Lymphovascular Invasion-The Prognostic Contribution of Related Molecular Markers. Histopathology, 55, 514-524. http://dx.doi.org/10.1111/j.1365-2559.2009.03425.X

[13] Inoue, K., Slaton, J.W., Karashima, T., Yoshikawa, C., Shuin, T., Sweeney, P., Millikan, R. and Dinney, C.P. (2000) The Prognostic Value of Angiogenesis Factor Expression for Predicting Recurrence and Metastasis of Bladder Cancer after Neoadjuvant Chemotherapy and Radical Cystectomy. Clinical Cancer Research, 6, 4866-4873.

[14] O’Brien, T., Cranston, D., Fuggle, S., Bicknell, R. and Harris, A.L. (1995) Different Angiogenic Pathways Characterize Superficial and Invasive Bladder Cancer. Cancer Research, 55, 510-513.

[15] Suzuki, K., Morita, T. and Tokue, A. (2005) Vascular Endothelial Growth Factor-C (VEGF-C) Expression Predicts Lymph Node Metastasis of Transitional Cell Carcinoma of the blaDder. International Journal of Urology, 12, 152-158. http://dx.doi.org/10.1111/j.1442-2042.2005.01010.x

[16] Black, P.C. and Dinney, C.P. (2007) Bladder Cancer Angiogenesis and Metastasis-Translation from Murine Model to Clinical Trial. Cancer and Metastasis Reviews, 26, 623-634. http://dx.doi.org/10.1007/s10555-007-9084-9

[17] Xu, S.J., Yang, L., Zeng, X., Zhang, M. and Wang, Z.T. (2006) Characterization of Compounds in the Chinese Herbal Drug Mu-Dan-Pi by Liquid Chromatography Coupled to Electrospray Ionization Mass Spectrometry. Rapid Communications in Mass Spectrometry, 20, 3275-3288. http://dx.doi.org/10.1002/rcm.2717

[18] Sun, G.P., Shen, Y.X., Zhang, L.L., Zhou, A.W., Wei, W. and Xu, S.Y. (2003) Research on Immunomodulatory and Antitumor Effects of Paeonol in a Mouse Model of HepA Hepatoma. Journal of Chinese Pharmaceutical Sciences, 19, 160-162.

[19] Sun, G.P., Shen, Y.X., Zhang, L.L., Wang, H., Wei, W. and Xu, S.Y. (2002) In Vitro Antitumor Effects of Paeonol. Acta Universitis Medicinalis Anhui, 37, 183-185.

[20] Ji, C.Y., Tan, S.Y. and Liu, C.Q. (2005) Effects of Paeonol on Apoptosis, Cell Cycle, and Patient Prognosis in Human Colon Cancer. Chinese Journal of Clinical Rehabilitation, 9, 122-124.

[21] Xu, S.P., Sun, G.P., Shen, Y.X., Wei, W., Peng, W.R. and Wang, H. (2007) Antiproliferation and Apoptosis Induction of Paeonol in $\mathrm{HepG}_{2}$ Cells. World Journal of Gastroenterology, 13, 250-256. http://dx.doi.org/10.3748/wjg.v13.i2.250

[22] Sun, G.P., Wan, X., Xu, S.P., Wang, H., Liu, S.H. and Wang, Z.G. (2008) Antiproliferation and Apoptosis Induction of Paeonol in Human Esophageal Cancer Cell Lines. Diseases of the Esophagus, 21, 723-729. http://dx.doi.org/10.1111/j.1442-2050.2008.00840.x

[23] Lee, H.J., Kim, S.A., Jeong, S.J., Han, I., Jung, J.H., Lee, E.O., Zhu, S., Chen, C.Y. and Kim, S.H. (2010) Paeonol Oxime Inhibits bFGF-Induced Angiogenesis and Reduces VEGF Levels in Fibrosarcoma Cells. PLoS ONE, 5, Article 
ID: e12358. http://dx.doi.org/10.1371/journal.pone.0012358

[24] Lin, M.Y., Lee, Y.R., Chiang, S.Y., Li, Y.Z., Chen, Y.S., Hsu, C.D. and Liu, Y.W. (2013) Cortex Moutan Induces Bladder Cancer Cell Death via Apoptosis and Retards Tumor Growth in Mouse Bladders. Evidence-Based Complementary and Alternative Medicine, 2013, Article ID: 207279, 8 p. http://dx.doi.org/10.1155/2013/207279

[25] Oh, G.S., Pae, H.O., Choi, B.M., Lee, H.S., Kim, I.K., Yun, Y.G., Kim, J.D. and Chung, H.T. (2004) Penta-O-galloyl$\beta$-D-Glucose Inhibits Phorbol Myristate Acetate-Induced Interleukin-8 [Correction of Intereukin-8] Gene Expression in Human Monocytic U937 Cells through Its Inactivation of Nuclear Factor-kB. International Immunopharmacology, 4, 377-386. http://dx.doi.org/10.1016/j.intimp.2003.10.010

[26] Choi, H.S., Seo, H.S., Kim, J.H., Um, J.Y., Shin, Y.C. and Ko, S.G. (2012) Ethanol Extract of Paeonia suffruticosa Andrews (PSE) Induced AGS Human Gastric Cancer Cell Apoptosis via Fas-Dependent Apoptosis and MDM2-p53 Pathways. Journal of Biomedical Science, 19, 82. http://dx.doi.org/10.1186/1423-0127-19-82

[27] Wang, S.C., Tang, S.W., Lam, S.H., Wang, C.C., Liu, Y.H., Lin, H.Y., Lee, S.S. and Lin, J.Y. (2012) Aqueous Extract of Paeonia Suffruticosa Inhibits Migration and Metastasis of Renal Cell Carcinoma Cells via Suppressing VEGFR-3 Pathway. Evidence-Based Complementary and Alternative Medicine, 2012, Article ID: 409823.

[28] Hsu, C.D., Chen, S.Y., Hung, L.C., Lin, C.P. and Lin, M.Y. (2010) The Effect of Cortex Mouta on Human Umbilical Vein Endotheial Cells and Epithelial Tumor Cells. Journal of Integrated Chinese and Western Medicine, 12, 1-9.

[29] Prayong, P., Barusrux, S. and Weerapreeyakul, N. (2008) Cytotoxic Activity Screening of Some Indigenous Thai Plants. Fitoterapia, 79, 598-601. http://dx.doi.org/10.1016/j.fitote.2008.06.007

[30] Hartwell, L.H. and Kastan, M.B. (1994) Cell Cycle Control and Cancer. Science, 266, 1821-1828. http://dx.doi.org/10.1126/science.7997877

[31] Vermeulen, K., Berneman, Z.N. and Van Bockstaele, D.R. (2003) Cell Cycle and Apoptosis. Cell Proliferation, 36, 165-175. http://dx.doi.org/10.1046/j.1365-2184.2003.00267.x

[32] Li, N., Fan, L.L., Sun, G.P., Wan, X.A., Wang, Z.G., Wu, Q., Wang, H. (2010) Paeonol Inhibits Tumor Growth in Gastric Cancer in Vitro and in Vivo. World Journal of Gastroenterology, 16, 4483-4490. http://dx.doi.org/10.3748/wjg.v16.i35.4483

[33] Cheng, Y.J., Jiang, H.S., Hsu, S.L., Lin, L.C., Wu, C.L., Ghanta, V.K. and Hsueh, C.M. (2010) XIAP-Mediated Protection of H460 Lung Cancer Cells against Cisplatin. European Journal of Pharmacology, 627, 75-84. http://dx.doi.org/10.1016/j.ejphar.2009.11.003

[34] Lu, C.C., Lin, M.Y., Chen, S.Y., Shen, C.H., Chen, L.G., Hsieh, H.Y., Chan, M.W. and Hsu, C.D. (2013) The Investigation of a Traditional Chinese Medicine, Guizhi Fuling Wan (GFW) as an Intravesical Therapeutic Agent for Urothelial Carcinoma of the Bladder. BMC Complementary and Alternative Medicine, 13, 44. http://dx.doi.org/10.1186/1472-6882-13-44

[35] Pandya, N.M., Dhalla, N.S. and Santani, D.D. (2006) Angiogenesis-A New Target for Future Therapy. Vascular Pharmacology, 44, 265-274. http://dx.doi.org/10.1016/j.vph.2006.01.005

[36] Koch, A.E., Polverini, P.J., Kunkel, S.L., Harlow, L.A., DiPietro, L.A., Elner, V.M., Elner, S.G. and Strieter, R.M. (1992) Interleukin-8 as a Macrophage-Derived Mediator of Angiogenesis. Science, 258, 1798-1801. http://dx.doi.org/10.1126/science.1281554

[37] Dvorak, H.F., Brown, L.F., Detmar, M. and Dvorak, A.M. (1995) Vascular Permeability Factor/Vascular Endothelial Growth Factor, Microvascular Hyperpermeability, and Angiogenesis. American Journal of Pathology, 146, 1029-1039. 
Scientific Research Publishing (SCIRP) is one of the largest Open Access journal publishers. It is currently publishing more than 200 open access, online, peer-reviewed journals covering a wide range of academic disciplines. SCIRP serves the worldwide academic communities and contributes to the progress and application of science with its publication.

Other selected journals from SCIRP are listed as below. Submit your manuscript to us via either submit@scirp.org or Online Submission Portal.
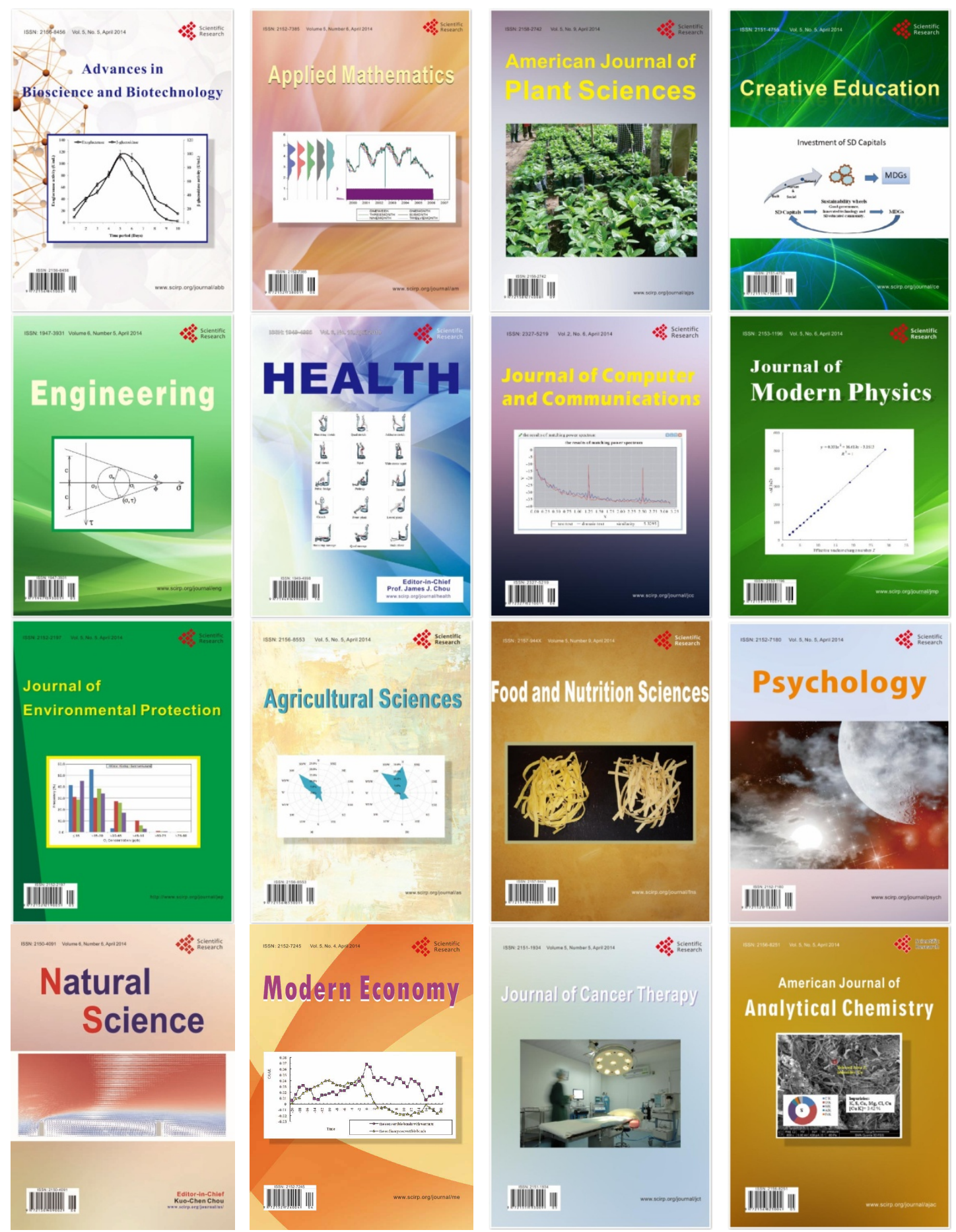